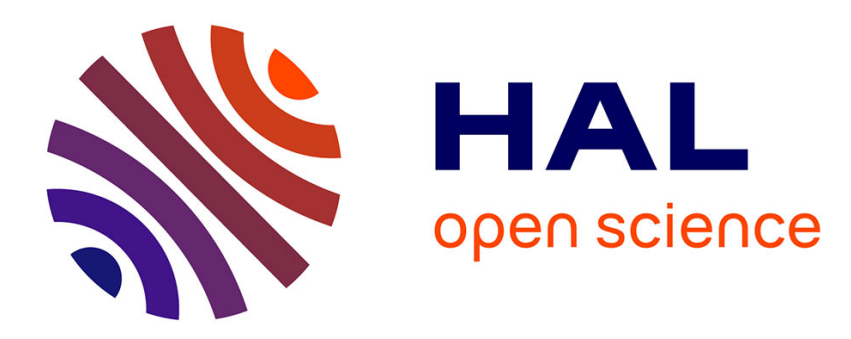

\title{
Familial idiopathic rapid eye movement sleep behavior disorder
}

\author{
Aurélie Pierre-Justin, Annie Lannuzel, Isabelle Arnulf
}

\section{To cite this version:}

Aurélie Pierre-Justin, Annie Lannuzel, Isabelle Arnulf. Familial idiopathic rapid eye movement sleep behavior disorder. Sleep Medicine, 2016, 10.1016/j.sleep.2016.04.015 . hal-01331186

\section{HAL Id: hal-01331186 \\ https://hal.sorbonne-universite.fr/hal-01331186}

Submitted on 13 Jun 2016

HAL is a multi-disciplinary open access archive for the deposit and dissemination of scientific research documents, whether they are published or not. The documents may come from teaching and research institutions in France or abroad, or from public or private research centers.
L'archive ouverte pluridisciplinaire HAL, est destinée au dépôt et à la diffusion de documents scientifiques de niveau recherche, publiés ou non, émanant des établissements d'enseignement et de recherche français ou étrangers, des laboratoires publics ou privés. 


\section{Familial idiopathic rapid eye movement sleep behavior disorder}

Aurélie Pierre-Justin ${ }^{1}$, Annie Lannuzel ${ }^{2}$, Isabelle Arnulf 1,3

${ }^{1}$ Sleep Disorder Unit, Pitie-Salpetriere University Hospital, Paris France

${ }^{2}$ Neurology Department, Pointe à Pitre University Hospital, Guadeloupe, France

${ }^{3}$ Pierre and Marie Curie University, Paris 6, France

Article submitted to: Sleep Medicine, Version 2

Type of article: Video Clinical Corner

Corresponding author: Isabelle Arnulf, Service des Pathologies du Sommeil, Hôpital Pitié-Salpêtrière, 47-83 boulevard de l'Hôpital, 75651 Paris Cedex 13, France

E-mail: isabelle.arnulf@aphp.fr

Phone: 33142167702

Fax: 33142167700 


\section{Key words}

REM sleep behavior disorder

$>$ Genetics

$>$ Idiopathic RBD

$>$ Synucleinopathy

$>$ Guadeloupean parkinsonism

$>$ Dream enactment

\section{Highlights}

$>$ A woman and her nephew had idiopathic REM sleep behavior disorder (iRBD)

This is the first multiplex family with polysomnography-proven iRBD

There were no dream enactment, parkinsonism or dementia in the other family members

$>$ This family, plus questionnaires and GBA mutations support genetic factors for iRBD 


\section{Introduction}

Idiopathic rapid eye movement sleep behavior disorder (iRBD) often heralds Parkinson's disease, dementia with Lewy bodies and multiple system atrophy [1]. Environmental and lifestyle factors (smoking, head injury, pesticide exposure, and farming) are potential risk factors for iRBD [2], whereas genetic contribution is suggested by increased history of dream enactment in first-degree relatives [3], and by higher GBA mutations frequency in patients with iRBD [4]. However, no multiplex family with several cases of polysomnography-proven iRBD has been yet published.

\section{Cases}

A 76-years old woman was referred from French West Indies for abnormal behaviors during sleep for 5 years. She had a hypertension and type 2 diabetes mellitus. Her husband reported that she was talking, singing and occasionally kicking or boxing him during the night, without any recall of these behaviors or associated dreams. She had no complain of motor and cognitive problem but reported hyposmia. Neurological examination and brain MRI were normal. The score at the Montreal cognitive assessment was $20 / 30$, but was hardly interpretable as she was illiterate. The videopolysomnography showed an abnormally enhanced muscle tone during $67 \%$ of REM sleep. Her behaviors during REM sleep included speaking, singing and crossing herself as if having a religious dream (Supplemental Video-clip). She needed a treatment combining melatonin $12 \mathrm{mg} / \mathrm{d}$ and clonazepam $2 \mathrm{mg} / \mathrm{d}$ to reduce the iRBD. 
One year later, her 67-years old nephew (who was middle-aged due to teen pregnancy in the grandmother, see family tree in Figure 1) living in metropolitan France since childhood was referred for abnormal behaviors during sleep for 3 years. He had hypertension. He reported frequent nightmares of fights, and fell several times out of bed, leading to injure himself and his wife (with face lacerations in both) to the point of sleeping in two separate rooms. He had no complain of motor, cognitive or olfaction problems. The neurological examination, cognitive test (Montreal cognitive assessment: 30/30) and brain MRI were normal. During the video-polysomnography, the muscle tone was abnormally enhanced during $32 \%$ of REM sleep and he had various complex behaviors including crying (Supplemental video-clip). He was successfully treated with melatonin $6 \mathrm{mg} / \mathrm{night}$. The family tree was established with the patients and after interviewing several family members by phone (Figure 1). Apart from the two reported cases with iRBD, no other cases with agitated nightmares, parkinsonism, tremor, walking and balance troubles, memory loss or dementia were identified. The patients agreed for their clinical study, family tree and video-clips to be displayed.

\section{Discussion}

This is, to the best of our knowledge, the first multiplex family with polysomnographyproven iRBD. The two patients were second-degree kindred (aunt and nephew), and not first-degree kindred as found in a recent multicenter questionnaire-based study [3]. In 12 different centers from Europe, North America and Japan, 312 patients with polysomnography-proven iRBD reported that $13.8 \%$ of their family-members (vs. $4.8 \%$ in 315 controls) had a history of dream enactment. The odd ratios were increased for both siblings and parents for dream enactment, but not for family history of tremor, walking and balance troubles, Parkinson disease, memory loss, or Alzheimer disease [3]. 
There was also no direct and proxy report of parkinsonism or dementia in our large multiplex family. Idiopathic RBD exposes affected patients to a high (around 92\%) risk of later synucleinopathy $[5,6]$. In the case of patients from the West Indees, neurologists may also suspect atypical Guadeloupean parkinsonism (resembling progressive supranuclear palsy) to later develop, because this disorder is highly frequent in West Indees [7], is comorbid with RBD (sometimes occurring before parkinsonism) in $80 \%$ of the patients [8], and is probably caused by the consumption of soursop, a tropical fruit containing annonaceous neurotoxins [7]. However, if the aunt had regularly eaten soursop throughout her life, this was not the case for her nephew raised in Europe, so that genetics may be more causal here than environmental exposure to soursop. Genetics may also predispose to iRBD. Indeed, mutations in GBA (the gene encoding for the enzyme glucocerebrosidase) are more frequent in patients with idiopathic RBD (10\%) than in patients with PD (4.6\%) or in controls $(1.3 \%)$ [4]. Numerically, GBA is the most important genetic risk factor for the development of PD, however the enzyme replacement therapy in patients with homozygous GBA mutation (leading to Gaucher disease) does not cross the blood brain barrier, hence would not protect them to develop PD, had they a concomitant iRBD [9]. DNA exome sequencing is next needed to explore whether more subtle DNA abnormalities can be found in the multiplex iRBD families.

\section{References}

[1]. Arnulf I. REM sleep behavior disorder: motor manifestations and pathophysiology. Mov Disord 2012; 27: 677-89.

[2]. Postuma R, Montplaisir J, Pelletier A, et al. Environmental risk factors for REM sleep behavior disorder - A multicentre case-control study. Neurology 2012; 79: 428-34. 
[3]. Dauvilliers Y, Postuma R, Ferini Strambi L, et al. Family history of idiopathic REM behavior disorder - A multicentre case-control study. Neurology 2013.

[4]. Gan-Or Z, Mirelman A, Postuma R, et al. GBA mutations are associated with Rapid Eye Movement Sleep Behavior Disorder. Ann Clin Transl Neurol 2015; 2: 941-5.

[5]. Postuma RB, Iranzo A, Hogl B, et al. Risk factors for neurodegeneration in idiopathic rapid eye movement sleep behavior disorder: a multicenter study. Ann Neurol $2015 ; 77: 830-9$.

[6]. Iranzo A, Fernandez-Arcos A, Tolosa E, et al. Neurodegenerative disorder risk in idiopathic REM sleep behavior disorder: study in 174 patients. PLoS One 2014; 9: e89741.

[7]. Lannuzel A, Hoglinger GU, Verhaeghe S, et al. Atypical parkinsonism in Guadeloupe: a common risk factor for two closely related phenotypes? Brain 2007; 130: 816-27.

[8]. De Cock VC, Lannuzel A, Verhaeghe S, et al. REM sleep behavior disorder in patients with guadeloupean parkinsonism, a tauopathy. Sleep 2007; 30: 1026-32. [9]. Beavan M, McNeill A, Proukakis C, et al. Evolution of prodromal clinical markers of Parkinson disease in a GBA mutation-positive cohort. JAMA Neurol 2015; 72: 201-8.

Disclosure: The authors report no disclosures or founding relevant to the manuscript.

Legend of the figure 1: Family tree including two relatives with idiopathic REM sleep behavior disorder (plain figures, II-3 and III-1). The other family members were interviewed (but not monitored) but had no dream enactment, tremor, parkinsonism or dementia (empty figures; dead persons are crossed of). 
Legend of the video-clip: During this excerpt in REM sleep (Part 1), the aunt speaks, sings, shouts "Satan (SAA -TAAN with a singing voice, as it can be made during a religious mass - Satan is the religious name of the devil)... (mumbling)... Satan (incomprehensible words)... Moses (a prophet name) Moses", sits in bed, gestures and crosses herself saying "in the name of the Father, ... of the Son and of the Holly Spirit", the classical gesture and formula referring to the three persons of the Christian Trinity), (incomprehensible words)... Satan go away!" as if having a religious dream, a scenic behavior typical of severe REM sleep behavior disorder. Her nephew (Part 2) cries while also sleeping in REM sleep (no words).

\section{Legend of Supplemental Figures}

Supplemental Figure A: Epoch lasting 30 s of polysomnography in Patient 1 during REM sleep and abnormal behavior (green marker: speaks and moves). EOG 1 and 2: left and right electro-oculograms; FP1-A2: left frontopolar/right mastoid bipolar EEG; C3-A2: left central/ right mastoid bipolar EEG; C3-01: left central/occipital bipolar EEG; EMG1: chin (levator menti) electromyogram; EMG2 and EMG3: right and left tibialis anterior muscle electromyogram; VTH: thoracic volume belt; VAB: abdominal volume belt.

Supplemental Figure B: Epoch lasting 30 s of polysomnography in Patient 2 during REM sleep and abnormal behavior (green markers: moves right hand). Other legends are the same as in Supplemental Figure A. 


\section{Familial idiopathic rapid eye movement sleep behavior disorder}

Aurélie Pierre-Justin ${ }^{1}$, Annie Lannuzel ${ }^{2}$, Isabelle Arnulf 1,3

${ }^{1}$ Sleep Disorder Unit, Pitie-Salpetriere University Hospital, Paris France

${ }^{2}$ Neurology Department, Pointe à Pitre University Hospital, Guadeloupe, France

${ }^{3}$ Pierre and Marie Curie University, Paris 6, France

Article submitted to: Sleep Medicine, Version 2

Type of article: Video Clinical Corner

Corresponding author: Isabelle Arnulf, Service des Pathologies du Sommeil, Hôpital Pitié-Salpêtrière, 47-83 boulevard de l'Hôpital, 75651 Paris Cedex 13, France

E-mail: isabelle.arnulf@aphp.fr

Phone: 33142167702

Fax: 33142167700 


\section{Key words}

REM sleep behavior disorder

$>$ Genetics

$>$ Idiopathic RBD

$>$ Synucleinopathy

$>$ Guadeloupean parkinsonism

$>$ Dream enactment

\section{Highlights}

$>$ A woman and her nephew had idiopathic REM sleep behavior disorder (iRBD)

This is the first multiplex family with polysomnography-proven iRBD

There were no dream enactment, parkinsonism or dementia in the other family members

$>$ This family, plus questionnaires and GBA mutations support genetic factors for iRBD 


\section{Introduction}

Idiopathic rapid eye movement sleep behavior disorder (iRBD) is a parasomnia which often heralds Parkinson's disease (PD) and dementia with Lewy bodies and multiple system atrophy[1]. Environmental and lifestyle factors (smoking, head injury, pesticide exposure, and farming) are potential risk factors for iRBD [2], whereas genetic contribution is suggested by increased history of dream enactment in first-degree relatives of patients with iRBD [3], and by higher GBA mutations frequency among patients with iRBD [4]. However, no multiplex family with several cases of polysomnography-proven iRBD has been published to date.

\section{Cases}

A 76-years old woman was referred from French West Indies for abnormal behaviors during sleep for 5 years. She had a hypertension treated with valsartan and hydrochlorothiazide, and a type 2 diabetes mellitus treated with glimepiride. Her husband reported that she was talking, singing and occasionally kicking or boxing him during the night, without any recall of these behaviors or associated dreams. She had no complain of motor and cognitive problem but reported hyposmia. Neurological examination and brain MRI were normal. The score at the Montreal cognitive assessment was $20 / 30$, but was hardly interpretable as she had never learned how to write, read or count. The video-polysomnography showed an abnormally enhanced muscle tone during $67 \%$ of REM sleep. Her behaviors during REM sleep included speaking ("Jesus", "Moses", "Satan"), singing and crossing herself as if having a religious 
dream (Supplemental Video-clip). She needed a treatment combining melatonin 12 $\mathrm{mg} / \mathrm{d}$ and clonazepam $2 \mathrm{mg} / \mathrm{d}$ to reduce the iRBD.

One year later, her 67-years old nephew (who was middle-aged due to teen pregnancy in the grandmother, see family tree in Figure 1) living in metropolitan France since childhood was referred for abnormal behaviors during sleep for 3 years. He had hypertension treated with lercanidipine. He reported frequent nightmares of fights, and fell several times out of bed, leading to injure himself and his wife (with frontal lacerations in both) to the point of sleeping in two separate rooms. He had no complain of motor, cognitive or olfaction problems. The neurological examination, cognitive test (Montreal cognitive assessment: 30/30) and brain MRI were normal. During the videopolysomnography, the muscle tone was abnormally enhanced during $32 \%$ of REM sleep and he had various complex behaviors including crying (Supplemental video-clip). He was successfully treated with melatonin $6 \mathrm{mg} / \mathrm{night}$. The family tree was established with the patients and after interviewing several family members by phone. Apart from the two reported cases with iRBD, no other cases with agitated nightmares, PD, tremor, walking and balance troubles, memory loss or dementia were identified. The patients agreed for their clinical study, family tree and video-clips to be displayed.

\section{Discussion}

This is, to the best of our knowledge, the first multiplex family with polysomnographyproven iRBD. The two patients were second-degree kindred (aunt and nephew), and not first-degree kindred as found in a recent multicenter questionnaire-based study [3]. In 12 different centers from Europe, North America and Japan, 312 patients with polysomnography-proven iRBD reported that $13.8 \%$ of their family-members (vs. $4.8 \%$ in 315 controls) had a history of dream enactment. The odd ratios were increased for 
both siblings and parents for dream enactment, but not for family history of tremor, walking and balance troubles, PD Parkinson disease, memory loss, or Alzheimer disease [3]. There was also no direct and proxy report of parkinsonism or dementia in our large multiplex family. Idiopathic RBD exposes affected patients to a high (around 92\%) risk of later synucleinopathy $[5,6]$. In the case of patients from the West Indees, neurologists may also suspect atypical Guadeloupean parkinsonism (resembling progressive supranuclear palsy) to later develop, because this disorder is highly frequent in West Indees [7], is comorbid with RBD (sometimes occurring before parkinsonism) in $80 \%$ of the patients [8], and is probably caused by the consumption of soursop, a tropical fruit containing annonaceous neurotoxins [7]. However, if the aunt had regularly eaten soursop throughout her life, this was not the case for her nephew raised in Europe, so that genetics may be more causal here than environmental exposure to soursop. Genetics may also predispose to iRBD. Indeed, mutations in GBA (the gene encoding for the enzyme glucocerebrosidase) (encoded by the GBA gene) are more frequent in patients with idiopathic RBD (10\%) than in patients with PD (4.6\%) or in controls (1.3\%) [4]. Numerically, GBA is the most important genetic risk factor for the development of PD, however the enzyme replacement therapy in patients with homozygous GBA mutation (leading to Gaucher disease) does not cross the blood brain barrier, hence would not protect them to develop PD, had they a concomitant iRBD [9]. Among 9 genetic loci associated with Parkinson's disease, two of them (SCARB2 and MAPT) are protective against $\mathrm{RBD}[10]$. DNA exome sequencing is next needed to explore whether more subtle DNA abnormalities can be found in the multiplex iRBD families.

\section{References}


[1]. Arnulf I. REM sleep behavior disorder: motor manifestations and pathophysiology. Mov Disord 2012; 27: 677-89.

[2]. Postuma R, Montplaisir J, Pelletier A, et al. Environmental risk factors for REM sleep behavior disorder - A multicentre case-control study. Neurology 2012; 79: 428-34. [3]. Dauvilliers Y, Postuma R, Ferini Strambi L, et al. Family history of idiopathic REM behavior disorder - A multicentre case-control study. Neurology 2013.

[4]. Gan-Or Z, Mirelman A, Postuma R, et al. GBA mutations are associated with Rapid Eye Movement Sleep Behavior Disorder. Ann Clin Transl Neurol 2015; 2: 941-5.

[5]. Postuma RB, Iranzo A, Hogl B, et al. Risk factors for neurodegeneration in idiopathic rapid eye movement sleep behavior disorder: a multicenter study. Ann Neurol $2015 ; 77: 830-9$.

[6]. Iranzo A, Fernandez-Arcos A, Tolosa E, et al. Neurodegenerative disorder risk in idiopathic REM sleep behavior disorder: study in 174 patients. PLoS One 2014; 9: e89741.

[7]. Lannuzel A, Hoglinger GU, Verhaeghe S, et al. Atypical parkinsonism in Guadeloupe: a common risk factor for two closely related phenotypes? Brain 2007; 130: 816-27.

[8]. De Cock VC, Lannuzel A, Verhaeghe S, et al. REM sleep behavior disorder in patients with guadeloupean parkinsonism, a tauopathy. Sleep 2007; 30: 1026-32. [9]. Beavan M, McNeill A, Proukakis C, et al. Evolution of prodromal clinical markers of Parkinson disease in a GBA mutation-positive cohort. JAMA Neurol 2015; 72: 201-8. [10]. Gan-Or Z, Girard SL, Noreau A, et al. Parkinson's disease genetic loci in rapid eye movement sleep behavior disorder. Journal of molecular neuroscience : MN 2015; 56: $617-22$.

Disclosure: The authors report no disclosures or founding relevant to the manuscript. 
Legend of the figure: Family tree including two relatives with idiopathic REM sleep behavior disorder (plain figures, II-3 and III-1). The other family members were interviewed (but not monitored) but had no dream enactment, parkinsonism or dementia (empty figures; dead persons are crossed of).

Legend of the video-clip: During this excerpt in REM sleep (Part 1), the aunt speaks, sings, shouts "Satan (SAA -TAAN with a singing voice, as it can be made during a religious mass - Satan is the religious name of the devil)... (mumbling)... Satan (incomprehensible words)... Moses (a prophet name) Moses", sits in bed, gestures and crosses herself saying "in the name of the Father, ... of the Son and of the Holly Spirit", the classical gesture and formula referring to the three persons of the Christian Trinity), (incomprehensible words)... Satan go away!" as if having a religious dream, a scenic behavior typical of severe REM sleep behavior disorder. Her nephew (Part 2) cries while also sleeping in REM sleep (no words).

\section{Legend of Supplemental Figures}

Supplemental Figure A: Epoch lasting 30 s of polysomnography in Patient 1 during REM sleep and abnormal behavior (green marker: speaks and moves). EOG 1 and 2: left and right electro-oculograms; FP1-A2: left frontopolar/right mastoid bipolar EEG; C3-A2: left central/ right mastoid bipolar EEG; C3-01: left central/occipital bipolar EEG; EMG1: chin (levator menti) electromyogram; EMG2 and EMG3: right and left tibialis anterior muscle electromyogram; VTH: thoracic volume belt; VAB: abdominal volume belt. 
Supplemental Figure B: Epoch lasting 30 s of polysomnography in Patient 2 during REM sleep and abnormal behavior (green markers: moves right hand). Other legends as in Supplemental Figure A. 